\title{
Low-Frequency 3D Wave Propagation Modeling of the 12 May 2008
}

\section{$M_{\mathrm{w}} 7.9$ Wenchuan Earthquake}

\author{
by M. Chavez, E. Cabrera, R. Madariaga, H. Chen, N. Perea, D. Emerson, A. Salazar, \\ M. Ashworth, Ch. Moulinec, X. Li, M. Wu, and G. Zhao
}

\begin{abstract}
The seismic potential of southern China is associated with the collision between the Indian and the Eurasian plates. This is manifested in the western Sichuan Plateau by several seismically active systems of faults, such as the Longmen Shan. The seismicity observed on the Longmen Shan fault includes recent events with magnitudes of up to 6.5, and the one of 12 May $2008 M_{\mathrm{w}} 7.9$ Wenchuan earthquake. Herewith, as part of an ongoing research program, a recently optimized threedimensional (3D) seismic wave propagation parallel finite-difference code was used to obtain low-frequency $(\leq 0.3 \mathrm{~Hz})$ 3D synthetic seismograms for the Wenchuan earthquake. The code was run on KanBalam (Universidad Nacional Autónoma de México, Mexico) and HECToR (UK National Supercomputing Service) supercomputers. The modeling included the U.S. Geological Survey $40 \times 315 \mathrm{~km}^{2}$ kinematic description of the earthquake's rupture, embedded in a $2400 \times 1600 \times 300 \mathrm{~km}^{3}$ physical domain, spatially discretized at $1 \mathrm{~km}$ in the three directions and a temporal discretization of $0.03 \mathrm{~s}$. The compression and shear wave velocities and densities of the geologic structure used were obtained from recently published geophysical studies performed in the Sichuan region. The synthetic seismograms favorably compare with the observed ones for several station sites of the Seismological and Accelerographic Networks of China, such as MZQ, GYA, and TIY, located at about 90, 500, and $1200 \mathrm{~km}$, respectively, from the epicenter of the Wenchuan event. Moreover, the comparisons of synthetic displacements with differential radar interferometry (DinSAR) ground deformation imagery, as well as of maximum velocity synthetic patterns with Mercalli modified intensity isoseist of the 2008 Wenchuan earthquake, are acceptable. 3D visualizations of the propagation of the event were also obtained; they show the source rupture directivity effects of the $M_{\mathrm{w}} 7.9$ Wenchuan event. Our results partially explain the extensive damage observed on the infrastructure and towns located in the neighborhood of the Wenchuan earthquake rupture zone.
\end{abstract}

\section{Introduction}

The seismicity of central-southern China is related to the collision between the Indian and the Eurasian plates. In the western Sichuan Plateau (eastern Tibetan Plateau), this collision generates several seismically active systems of faults, such as the Longmen Shan fault system (Densmore et al., 2007; Robert et al., 2009), where the hypocenter of the 12 May $2008 M_{\mathrm{w}} 7.9$ Wenchuan earthquake is located at a depth of 10-20 km (U.S. Geological Survey [USGS] data, see Data and Resources section). Among other manifestations of the collision, recent Global Positioning System measurements of crustal motion in the central eastern Tibetan Plateau

*Also at the Laboratoire de Géologie CNRS-ENS, Département des Géosciences, ENS, Paris, France. and its adjacent foreland indicate a shortening of about $3 \mathrm{~mm} /$ year within the Longmen Shan region; this suggests an average recurrence interval of seismic activity from 2000 to 10,000 years (Burchfield et al., 2008). This Longmen Shan region is located between the western Sichuan Plateau and the Sichuan basin (Fig. 1). The Sichuan basin is part of the Yangtze craton, and the collision between the latter and the Tibetan Plateau is supposed to have produced the thickening of the lower crust and the uplift of the western Sichuan Plateau (Wang et al., 2007). Another manifestation of this collision is the seismicity in the region: it includes earthquakes with magnitudes $\leq 6.5$ on and close to the Longmen Shan fault system and with magnitudes up to 8 in its vicinity, at least since 1879 , until the 12 May $2008 M_{\mathrm{w}} 7.9\left(M_{s} 8\right)$ event, as shown in 


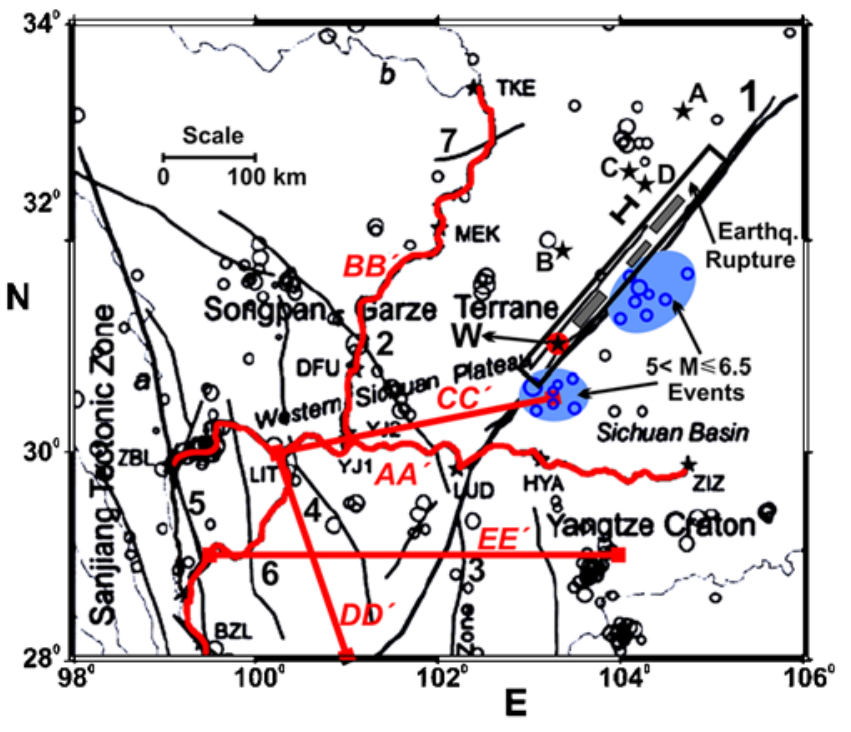

Figure 1. Fault systems in the region of interest are identified by bold lines with a number (modified from Wang et al., 2007): 1, Longmen Shan; 2, Xianshuihe; 3, Anninghe; 4, Garze-Litang; 5, Jinshajiang; 6, Xiangcheng; 7, Longriba. Rivers are indicated by thin lines: a, Jinshajiang; b, Yellow. Open circles denote the epicenters of earthquakes with magnitudes $>5$ that occurred from 1960 to 2007. The epicenters of $M \geq 7.2$ historical earthquakes are identified with the letters A-D and with W for the 12 May 2008 Wenchuan event (see Table 1). $\mathrm{AA}^{\prime}$ and $\mathrm{BB}^{\prime}$ correspond to the seismic profiles studied by Wang et al., (2007); $\mathrm{CC}^{\prime}, \mathrm{DD}^{\prime}$, and $\mathrm{EE}^{\prime}$ identify the seismic profiles studied by Xu et al., (2007). The surface projection of the rupture area of the 12 May $2008 M_{\mathrm{w}} 7.9$ Wenchuan earthquake is represented by the long rectangle, and its inner rectangles identify the areas with kinematic slips $>6$ to $9 \mathrm{~m}$ suggested by $\mathrm{Ji}$ and Hayes (2008). The color version of this figure is available only in the electronic edition.

Figure 1 and Table 1. Notice in Figure 1 that the rupture area of the 2008 Wenchuan event was $\sim 40 \times 315 \mathrm{~km}^{2}$, and its largest kinematic slips of $\sim 6$ to $9 \mathrm{~m}$ (Ji and Hayes, 2008), represented by three inner rectangles of its rupture area, are located between the two concentrations of events with magnitudes $\leq 6.5$ that occurred from 1960 to 2007 and are identified by open circles inside the shaded ellipsoids in Figure 1.

In this work, a recently optimized 3D seismic wave propagation parallel finite-difference (3DOPFD) code (Cabrera et al., 2007; Chavez et al., 2008), based on the staggered finite-difference method proposed by Madariaga (1976) for

Table 1

Large Magnitude $(\mathbf{M} \geq 7.2)$ Earthquakes in/near the Longmen Shan Fault System, 1879-2009

\begin{tabular}{ccccc}
\hline Event & $\begin{array}{c}\text { Date } \\
\text { (dd/mm/yyyy) }\end{array}$ & MMI* & M & $\begin{array}{c}\text { Depth of } \\
\text { Earthquake }(\mathrm{km})\end{array}$ \\
\hline A & $01 / 07 / 1879$ & XI & 8.0 & - \\
B & $25 / 08 / 1933$ & X & 7.5 & - \\
C & $16 / 08 / 1976$ & IX & 7.2 & 15 \\
D & $23 / 08 / 1976$ & VIII+ & 7.2 & 23 \\
W & $12 / 05 / 2008$ & XI & 8.0 & 10 \\
\hline
\end{tabular}

*MMI is the maximum Mercalli modified intensity of the earthquakes. (See Fig. 1 for the epicentral location of the events.) the simulation of the dynamic propagation of a circular fault, was used to obtain low-frequency $(\leq 0.3 \mathrm{~Hz})$ 3D velocity synthetics of the 12 May $2008 M_{\mathrm{w}} 7.9$ Wenchuan earthquake. The supercomputers KanBalam and HECToR (see Data and Resources section) were used to run the code. This paper is divided into the following sections: a description of the mathematical-computational model used, a discussion of the geotectonic characteristics of the Longmen Shan fault system region, a presentation of examples of recordings obtained for the Wenchuan $M_{\mathrm{w}} 7.9$ event, the presentation of the results obtained from its modeling, and, finally, the main conclusions of the work.

\section{Mathematical and Computational 3D Finite-Difference Model}

Since Madariaga's (1976) study of the radiation characteristics of a circular fault, further developments of the staggered grid finite-difference method have been proposed for the modeling of the wave propagation problem in $2 \mathrm{D}$ and 3D media. Examples include the 2D, $S H$ and $P-S V$ wave propagation in heterogeneous media (Virieux, 1984, 1986); a 2D fourth-order finite-difference approach to generate $P-S V$ seismograms (Levander, 1988); the 2D propagation of $S H$ waves using an irregular mesh (Moczo, 1989); the 3D elastic wave propagation problem (Olsen, 1994); the 3D seismic wave propagation in an elastic medium (Graves, 1996); and the use of nonuniform grid spacing on the 3D elastic seismic wave propagation problem (Pitarka, 1999). The method has also been successfully applied for the modeling of the wave propagation of recent seismic events; for example, the $1992 M_{s} 7.3$ Landers, California, earthquake (Olsen et al., 1997), the 28 September $2004 M_{\mathrm{w}} 6.0$ Parkfield, California, earthquake (Liu et al., 2006; Custodio et al., 2009), as well as for an $M_{s} 7.75$ earthquake scenario in the San Andreas fault (Olsen et al., 1995) and the 1906 San Francisco, California, earthquake (Aagaard et al., 2008a, 2008b).

Herewith, first a synthesis of the elastodynamic formulation (based on Minkoff, 2002) and a description of the 3D optimized parallel algorithm (Cabrera et al., 2007; Chavez et al., 2008) of the elastic wave propagation problem are presented.

Elastodynamic Formulation of the Elastic Wave Propagation Problem

For the velocity-stress formulation of the elastic wave equation in a 3D medium occupying a volume $V$ and boundary $S$, the medium may be described using Lamé parameters $\lambda(\bar{x})$ and $\mu(\bar{x})$ and mass density $\rho(\bar{x})$, where $(\bar{x}) \in \mathfrak{R}^{3}$ (Minkoff, 2002). The velocity-stress form of the elastic wave equation consists of nine coupled, first-order partial differential equations for the three particle velocity vector components $\nu_{i j}(\bar{x}, t)$ and the six independent stress tensor components, $\sigma_{i j}(\bar{x}, t)$, where $i, j=1,2,3$, and assuming that $\sigma_{i j}(\bar{x}, t)=\sigma_{j i}(\bar{x}, t)$ : 


$$
\frac{\partial v_{i}(\bar{x}, t)}{\partial t}-b(\bar{x}) \frac{\partial \sigma_{i j}(\bar{x}, t)}{\partial x_{j}}=b(\bar{x})\left[f_{i}(\bar{x}, t)+\frac{\partial m_{i j}^{a}(\bar{x}, t)}{\partial x_{j}}\right]
$$

and

$$
\begin{aligned}
& \frac{\partial \sigma_{i j}(\bar{x}, t)}{\partial t}-\lambda(\bar{x}) \frac{\partial v_{k}(\bar{x}, t)}{\partial x_{k}} \delta_{i j}-\mu(\bar{x})\left[\frac{\partial v_{i}(\bar{x}, t)}{\partial x_{j}}+\frac{\partial v_{j}(\bar{x}, t)}{\partial x_{i}}\right] \\
& \quad=\frac{\partial m_{i j}^{s}(\bar{x}, t)}{\partial t},
\end{aligned}
$$

where $b(\bar{x})=1 / \rho(\bar{x}), f_{i}(\bar{x}, t)$ is the force source tensor, $m_{i j}^{a}(\bar{x}, t)=1 / 2\left[m_{i j}(\bar{x}, t)-m_{j i}(\bar{x}, t)\right]$ and $m_{i j}^{s}(\bar{x}, t)=1 / 2$ $\left[m_{i j}(\bar{x}, t)+m_{j i}(\bar{x}, t)\right]$ are the antisymmetric and symmetric source moment tensors, and $\delta_{i j}$ is the Kronecker delta function. The traction boundary condition (normal component of stress) must satisfy

$$
\sigma_{i j}(\bar{x}, t) n_{j}(\bar{x})=t_{i}(\bar{x}, t)
$$

for $\bar{x}$ on $S$, where $t_{i}(\bar{x}, t)$ are the components of the timevarying surface traction vector and $n_{j}(\bar{x})$ are the components of the outward unit normal to $S$. The initial conditions on the dependent variables are specified at $V$ and on $S$ at time $t=t_{0}$ by

$$
v_{i}(\bar{x}, t)=v_{i}^{0}(\bar{x}), \quad \sigma_{i j}(\bar{x}, t)=\sigma_{i j}^{0}(\bar{x}) .
$$

If the orientation of interest is on a particular axis defined by the dimensionless unit vector $e$, then the particle velocity seismogram is given by

$$
\begin{aligned}
v_{e}\left(\bar{x}_{r}, t\right) & =e_{k} v_{k}\left(\bar{x}_{r}, t\right) \\
& =e_{1} v_{1}\left(\bar{x}_{r}, t\right)+e_{2} v_{2}\left(\bar{x}_{r}, t\right)+e_{3} v_{3}\left(\bar{x}_{r}, t\right) .
\end{aligned}
$$

In our simulations, the source was assumed to have zero resultant force and moment so that $f_{i}(\bar{x}, t)=0$ and $m_{i j}^{a}(\bar{x}, t)=0$. The symmetric moment tensor density is defined as $m=$ $\mu(\bar{x}) D(\bar{x})$, where $D$ is the slip. For a general fault shape, we project the moment density into the closest points on the grid (Olsen et al., 1997).

Parallel Implementation of the 3D Optimized Parallel Finite-Difference Code

The finite-difference staggered algorithm applied to equations 1-4 is an explicit scheme that is second-order accurate in time and fourth-order accurate in space. Staggered grid storage allows the partial derivatives to be approximated by centered finite differences without doubling the spatial extent of the operators, thus providing more accuracy. The discretization of the 3D spatial grid is such that $x_{i}=x_{0}+$ $(i-1) h_{x}, y_{j}=y_{0}+(j-1) h_{y}$, and $z_{k}=z_{0}+(k-1) h_{z}$ for $i=1,2,3, \ldots I, j=1,2,3, \ldots, J$, and $k=1,2,3, \ldots, K$, respectively. Here $x_{0}, y_{0}, z_{0}$ are the minimum grid values, and $h_{x}, h_{y}, h_{z}$ indicate the distance between points in the three coordinate directions. The time discretization is defined by $t_{l}=t_{0}+(l-1) h_{t}$ for $l=1,2,3, \ldots, L$. Here, $t_{0}$ is the minimum time and $h_{t}$ is the time increment. Further details about the (velocity-stress) staggered finite-difference scheme on which the algorithm used is based can be found in Madariaga (1976), Olsen (1994), Graves (1996), and Moczo et al. (2005).

The best parallel programs are those where each processor gets almost the same amount of work while trying to minimize communications. Using this kind of partition, the global domain is decomposed into smaller pieces (subdomains) and distributed among all processors; therefore, each processor solves its own subdomain problem.

We use message passing interface (MPI) to parallelize the 3DOPFD code. In particular, MPI_Bcast was used to communicate the geometry and physical properties of the problem before starting the wave propagation loop, and MPI_Cart_Shift and MPI_SendRecv were used to update the velocity and stress calculations at each time step. The fourthorder spatial finite-difference scheme requires two additional planes of memory on every face of the subdomain to compute the finite-difference solution independently from the other processes; therefore, we allocate padded subdomains of memory for every face of the subdomain cube to ensure the precise functioning of the staggered finite-difference scheme used.

Other details about the implementation, tests, and benchmark studies performed on different supercomputer platforms of the developed 3DOPFD optimized code can be found in Cabrera et al. (2007) and Chavez et al. (2008).

\section{Geotectonic Characteristics of the Region around the Longmen Shan Fault System}

With respect to the structural geotectonic characteristics of the region of interest (Fig. 1), Li et al. (2006) recently proposed 14 crustal models for mainland China. Those models were the result of $\sim 90$ seismic refraction/wide angle reflection profiles and included representative crustal seismic velocity (in particular of compression waves, $V_{P}$ )-depth columns, associated to the 14 tectonic units of China proposed by T. K. Huang et al. in 1980 (quoted by Li et al. 2006). In this work, the geotectonic characteristics of the depth columns F, H, and L, of figure 5 from Li et al. (2006) were used because they include the region depicted in Figure 1, as well as other northeastern regions that were included in the modeled physical domain of the $M_{\mathrm{w}} 7.9$ Wenchuan earthquake (Fig. 2).

At a regional level, Wang et al. (2007) performed active source seismic refraction and wide-angle reflection (i.e., deep seismic sounding) experiments in the western Sichuan Plateau and the Sichuan basin region. From those experiments, Wang et al. (2007) obtained 2D seismic profiles of the transects $\mathrm{AA}^{\prime}$ (which include the Longmen Shan fault system) and $\mathrm{BB}^{\prime}$ shown in Fig. 1. The lengths of both transects were of $\sim 700 \mathrm{~km}$, and the resolution depths were up to $80 \mathrm{~km}$. A reference altitude of $3 \mathrm{~km}$ (i.e., reflecting the varying topography of the region) was used for processing the information (Wang et al., 2007). Based on those seismic 


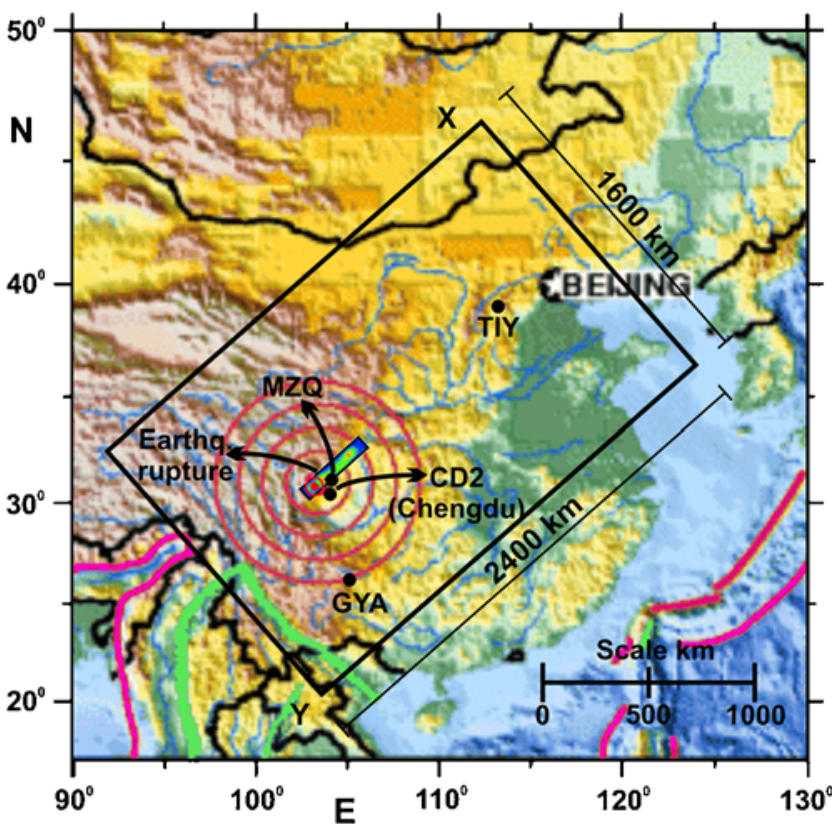

Figure 2. The surficial projection of the $2400 \times 1600 \times$ $300 \mathrm{~km}^{3}$ volume used to discretize the region of interest. Small rectangle, the $315 \times \sim 40 \mathrm{~km}^{2}$ southwest-northeast-directed rupture area of the 12 May 2008 Wenchuan $M_{\mathrm{w}} 7.9$ earthquake; star, locations of its epicenter; dots, the CD2, GYA, and TIY seismographic stations sites; MZQ, the accelerographic station site of the China Seismographic and Accelerographic Networks (modified from Ji and Hayes, 2008). The color version of this figure is available only in the electronic edition.

profiles, they proposed the 3D geotectonic structure of about $700 \times 700 \times 80 \mathrm{~km}^{3}$ shown in Figure 3, as well as the corresponding compression velocity $\left(V_{P}\right)$ and density values of the crust layers up to the mentioned $80 \mathrm{~km}$ depth (Wang et al., 2007). Notice in Figure 3 that the Wang et al. (2007) crust layering proposal for the Longmen Shan region consists of (almost) horizontal layers for the $700 \times 700 \mathrm{~km}^{2}$ studied region.

The variation of the shear wave velocity, $V_{S}$, with depth for the same Sichuan region studied by Wang et al. (2007) (i.e., the seismic profiles $\mathrm{CC}^{\prime}, \mathrm{DD}^{\prime}$, and $\mathrm{EE}^{\prime}$ of Fig. 1) was obtained by Xu et al. (2007). They applied the receiver function technique to very broadband (VBB) recordings of teleseismic earthquakes in 25 temporal stations, disseminated in the Sichuan region at altitudes from 0 (on the Sichuan basin) to $4 \mathrm{~km}$ (on the western Sichuan Plateau); see Figure 1. Among other results, they obtained the $V_{S}$ crustal velocities up to a depth of $80 \mathrm{~km}$ for profiles that included some station sites located in the vicinity of the Longmen Shan fault system. Of particular interest for this work is the result shown in figure 10 of $\mathrm{Xu}$ et al. (2007): in the first $7 \mathrm{~km}$ of depth; the $V_{S}$ values are significantly inferior to $3 \mathrm{~km} / \mathrm{s}$. Xu et al. (2007) also proposed ratios of $V_{P} / V_{S}$ for the mentioned station sites, which, on average are equal to $1.86 \pm 0.07$.

It is important to mention that the results obtained by Wang et al. (2007) and $\mathrm{Xu}$ et al. (2007) show a smooth 2D variation of the $V_{P}, V_{S}$, and density values found for the region included in Figure 1 and Figure 3. Those values reflect the properties of the layers forming the topography of the Sichuan region shown in these two figures; for example, the recording station sites MC03 ( 15 km of the Longmen Shan fault system) and MC04 of figure 10 of $\mathrm{Xu}$ et al. (2007), located at altitudes of 2 and $4 \mathrm{~km}$, respectively.

Observations of the 12 May $2008 M_{\mathrm{w}} 7.9$ Wenchuan Earthquake

A large number of seismographs and accelerographs of the Seismological Network of China (SNC) and of the China Digital Strong Motion Network (CDSMN) recorded the 12 May 2008 Wenchuan event. However, the accelerographic information recorded for this event by the 478 instruments of the CDSMN (Yuan and Sun, 2008) is not available to the public for the time being (except, in this work, the ones recorded at the station MZQ; see Fig. 2 and the Data and Resource section) and from the $48 \mathrm{VBB}$ digital seismographs of the SNC, the information from 17 of which was available for this study (see Data and Resource section). Unfortunately, most of the seismograms were saturated for the mainshock of the 2008 Wenchuan event.

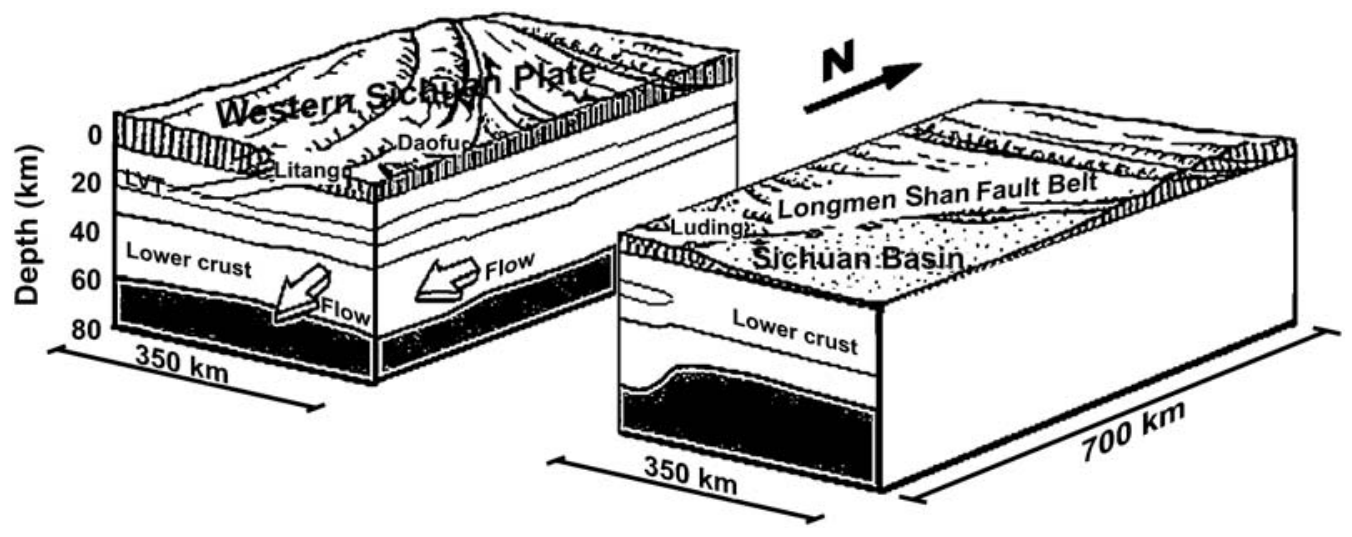

Figure 3. 3D diagram of the crustal kinematic model for the eastern margin of the Tibetan Plateau, constructed from 2D crustal structures obtained from the seismic profiles $\mathrm{AA}^{\prime}$ and $\mathrm{BB}^{\prime}$ of Figure 1 (modified from Wang et al., 2007). 
In Figures 4-6, we present examples of the velocity VBB seismograms recorded for the $M_{s} 8$ Wenchuan earthquake at CD2, GYA, and TIY stations (see Fig. 2), located at about $90 \mathrm{~km}$ (near field), $500 \mathrm{~km}$ (intermediate field) and $1200 \mathrm{~km}$ (far field) from its epicenter, respectively. Notice in those figures that the seismograms at $\mathrm{CD} 2$ station are saturated from $\sim 190$ to 550 s (Fig. 4); however, the ones for GYA are unsaturated, from $\sim 190$ to $290 \mathrm{~s}$ and saturated from $\sim 290$ to $\sim 450 \mathrm{~s}$ (Fig. 5), and the TIY records are unsaturated from $\sim 260$ to $380 \mathrm{~s}$ and saturated from $\sim 380$ to $500 \mathrm{~s}$ (Fig. 6) — that is, the maximum amplitudes of the ground motion velocities at those stations could not be recorded because the VBB seismographs of the SNC reached their maximum range. Therefore, for the present study, for which the main objective is the generation of low-frequency synthetic seismograms for the 12 May 2008 Wenchuan event, we decided to use the selected unsaturated time windows of the velocity recordings of stations GYA and TIY shown in Figure 5 and Figure 6, respectively, as well as to low pass filter them for frequencies $\leq 0.3 \mathrm{~Hz}$ in order to compare them with the synthetics seismograms.

Because the recordings of stations GYA and TIY were obtained at epicentral distances of $\sim 500 \mathrm{~km}$ and $\sim 1200 \mathrm{~km}$ and because we were also interested in using near-field recordings for the study, this information was provided by the accelerograms recorded at station MZQ, located at about $90 \mathrm{~km}$ from the epicenter of the $M_{\mathrm{w}} 7.9$ Wenchuan earthquake, (Fig. 2). In the top panel of Figure 7, we show the vertical component of those recordings. Notice that, in this case, the record is not saturated and reached a maximum acceleration of $6.23 \mathrm{~m} / \mathrm{s}^{2}$ and that the duration of its most intense part was $\sim 25 \mathrm{~s}$. The record was integrated once to obtain the associated velocity signal (middle panel of Fig. 7), and then a time window of $100 \mathrm{~s}$ was selected and low-pass filtered for frequencies $\leq 0.3 \mathrm{~Hz}$ (bottom panel of Fig. 7). This MZQ velocity seismogram and the previously mentioned seismograms from GYA and TIY stations were compared with the synthetic seismograms obtained with the 3DOPFD code for the 12 May 2008 Wenchuan $M_{\mathrm{w}} 7.9$ earthquake.

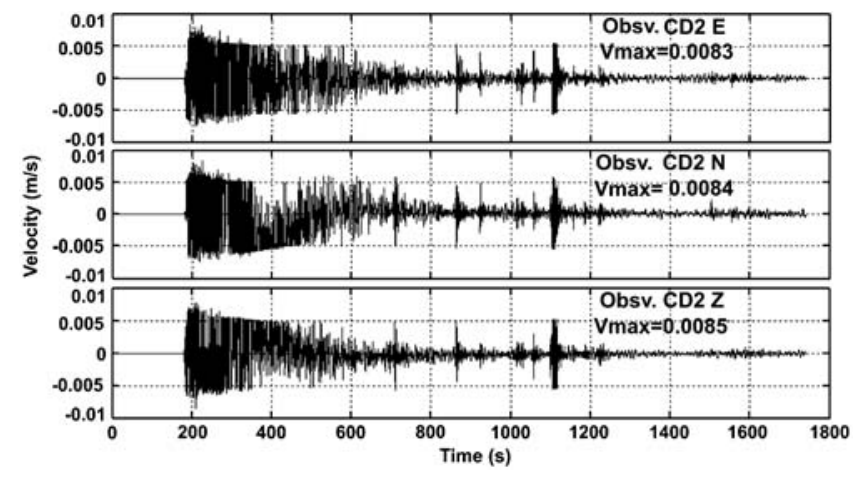

Figure 4. Very broadband velocity (saturated from $\sim 190$ to $\sim 550 \mathrm{~s}$ ) seismograms in the East (E), North $(\mathrm{N})$, and vertical (Z) directions observed at station CD2 (see Fig. 2) of the Seismological Network of China for the 12 May $2008 M_{\mathrm{w}} 7.9$ Wenchuan earthquake.

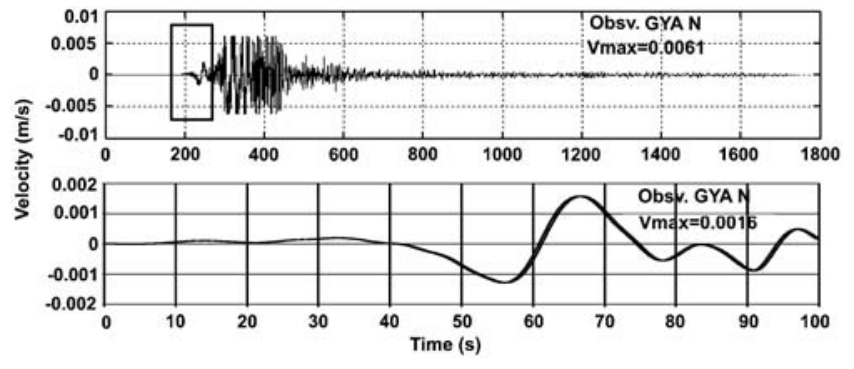

Figure 5. Very broadband velocity (saturated from $\sim 290$ to $\sim 550 \mathrm{~s})$ seismograms in the North $(\mathrm{N})$ direction observed at station GYA (see Fig. 2) for the 12 May $2008 M_{\mathrm{w}} 7.9$ Wenchuan earthquake and the 100 -s (unsaturated, from $\sim 190$ to $\sim 290$ s) selected time window filtered for frequencies $\leq 0.3 \mathrm{~Hz}$.

\section{D Modeling of the Wave Propagation of the 12 May 2008 Wenchuan $M_{\mathrm{w}} 7.9$ Earthquake}

Geologic and Geophysical Parameters of the Modeling

The 3DOPFD code was used for the computation of lowfrequency synthetic seismograms for the $M_{\mathrm{w}} 7.9$ Wenchuan earthquake. The information required by the code about the geometric and mechanical properties $\left(V_{P}, V_{S}\right.$, and densities) of the physical domain of interest, the seismic source (strike, dip, rake, and slip) and the spatial and temporal discretization parameters are discussed below.

With respect to the selected physical domain, the surface projection of the 2400 (length) $\times 1600$ (width) $\times$ 300 (depth) $\mathrm{km}^{3}$ volume used in this work is presented in Figure 2. Notice in this figure that the surface includes the projection of the $315 \times 40 \mathrm{~km}^{2}$ Wenchuan $M_{\mathrm{w}} 7.9$ earthquake rupture area (Ji and Hayes, 2008), as well as the locations of the recording stations MZQ, CD2, GYA, and TIY. The 300-km depth of the volume took into account the possible generation of long-period surface waves in the intermediate (GYA station) and far (TIY) fields of the considered assumed domain. The geologic structure assumed for this volume is depicted in Figure 8. Notice that this structure includes seven layers with a total thickness of $48 \mathrm{~km}$ resting on a last one of $252 \mathrm{~km}$ and that the first layer (starting from

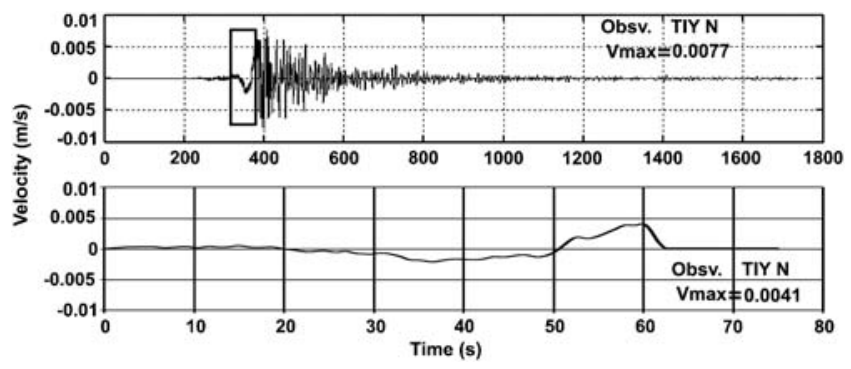

Figure 6. Very broadband velocity (saturated from $\sim 380$ to $\sim 500 \mathrm{~s})$ seismograms in the North $(\mathrm{N})$ direction observed at station TIY (see Fig. 2) for the 12 May $2008 M_{\mathrm{w}} 7.9$ Wenchuan earthquake and the 62-s (unsaturated) selected time window filtered for frequencies $\leq 0.3 \mathrm{~Hz}$. 


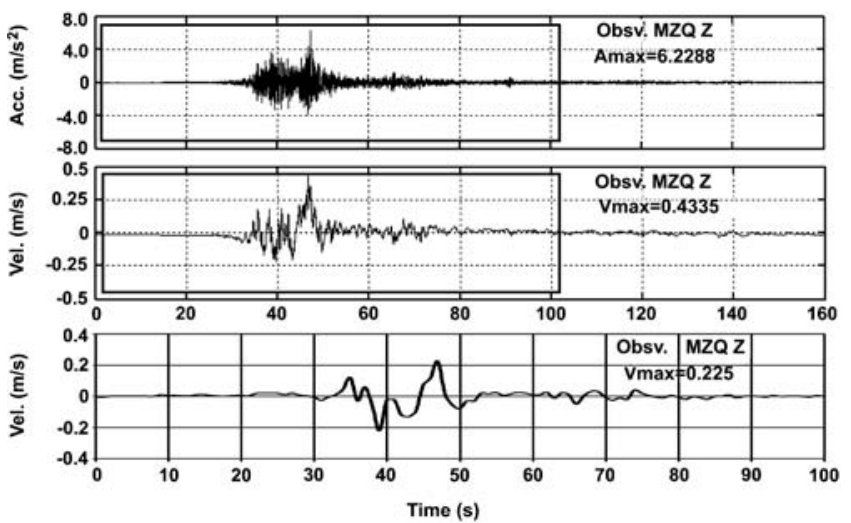

Figure 7. Recorded accelerogram and its velocity seismogram in the vertical (Z) direction observed at station MZQ (see Fig. 2) for the 12 May $2008 M_{\mathrm{w}} 7.9$ Wenchuan earthquake and the 100-s selected time window filtered for frequencies $\leq 0.3 \mathrm{~Hz}$.

the top) has a shear wave velocity of propagation considerably smaller than the other layers.

It is relevant to mention that the geologic structure shown in Figure 8, and its corresponding thicknesses, $V_{P}$, $V_{S}$, and densities, were adopted here as a first approach (which should be improved in a future study when more geologic information becomes available) to the modeling of the geologic structure for the region of interest depicted in Figure 2. The geologic structure of Figure 8 took the regional structural geotectonic and geophysical information available for the Sichuan region into account; that is, in the first instance, the selection considered the geometry and layering of the crust of the kinematic volume (about $700 \times 700 \times$ $80 \mathrm{~km}^{3}$ ) proposed by Wang et al. (2007) and shown in Figure 3 for the region surrounding and including the seismic source of the $M_{\mathrm{w}} 7.9$ Wenchuan earthquake (Robert et al., 2009). Based on seismologic and gravity data, Robert et al. (2009) concluded that the hypocenter of the 12 May 2008 Wenchuan earthquake is located very close to a westwarddipping interface (starting close to the surface at the Longmen Shan front and flattening at $\sim 15 \mathrm{~km}$ depth) between the lower crust under the Sichuan basin and the eastern Songspan-Garze terrane (see fig. 2 of Robert et al., 2009).

With respect to the thicknesses, the $V_{P}, V_{S}$, and densities of the layers included in Figure 8 (and particularly the most surficial ones), we took into account the findings about those properties obtained by Wang et al. (2007), Xu et al. (2007), and $\mathrm{Li}$ et al. (2006), which were discussed previously. The $V_{P}, V_{S}$, and densities of the layers suggested by Wang et al. (2007) and Xu et al. (2007) were obtained for the seismic profiles $\mathrm{AA}^{\prime}, \mathrm{BB}^{\prime}$ and $\mathrm{CC}^{\prime}, \mathrm{DD}^{\prime}, \mathrm{EE}^{\prime}$ of Figure 1 for reference altitudes from 0 to $4 \mathrm{~km}$ and up to a depth of $80 \mathrm{~km}$, taking into account the layering and the mechanical properties of the high and low altitudes of the Sichuan region and its vicinity. Therefore, we think that, even though we are not including the topography of the Sichuan region in our flat layering model shown in Figure 8, the synthetic seismograms of the Wenchuan $M_{s} 8$ earthquake computed here with the geologic

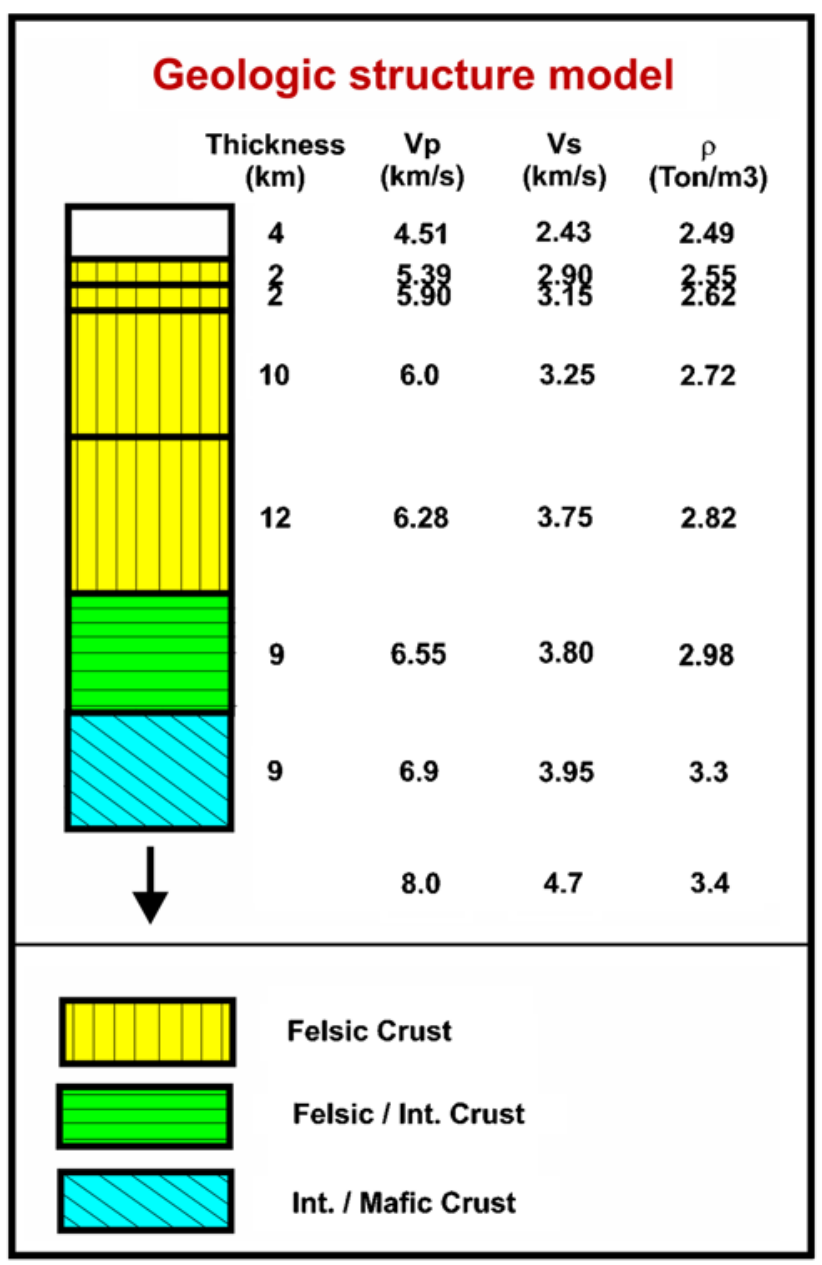

Figure 8. The geologic structure adopted in this work for the volume used to discretize the region of interest (see Fig. 2). The structure was obtained from averaging the China-regional results of Li et al. (2006) and the local results (see Fig. 1 and Fig. 3) for the Sichuan region of Wang et al. (2007) and Xu et al. (2007). The color version of this figure is available only in the electronic edition.

structure of Figure 8 for sites at epicentral distances in the near field (e.g., the MZQ station site) and intermediate field (GYA recording station site) would better reflect the geologic conditions of the Sichuan region than those for the far field (e.g., the TIY recording station site) sites located at large epicentral distances and with different geologic conditions than the ones of the Sichuan region, particularly for their surficial layers, as discussed by Li et al. (2006).

\section{Seismic Source and Discretization Parameters of the Modeling}

In this work, the kinematic slip distribution shown in Figure 9, obtained by Ji and Hayes (2008), as well as the strike, dip, and rake angles of the event listed by the USGS (see Data and Resources section) for the $M_{\mathrm{w}} 7.9$ Wenchuan earthquake were adopted for the modeling. The slip distribution proposed by Ji and Hayes (2008) was obtained from the inversion of teleseismic wave forms and using a discretization 
of the seismic source area of $315 \times \sim 40 \mathrm{~km}$, with $21 \times 8$ cells of $15 \times 5 \mathrm{~km}^{2}$ in the strike and dip directions of the event, respectively. As shown in Figure 9, they obtained maximum slips of $\sim 9 \mathrm{~m}$ in two regions of the rupture area, one at $\sim 50 \mathrm{~km}$ and the second at $\sim 180 \mathrm{~km}$ from the hypocenter. This slip distribution was converted into a moment rate distribution and used as the seismic source in the finitedifference code.

The earthquake rupture had a strike of $229^{\circ}$, a dip of $33^{\circ}$, and a rake of $141^{\circ}$, with a southwest-northeast rupture direction and total rupture duration of $\sim 120 \mathrm{~s}$. A uniform rupture velocity of $2.75 \mathrm{~km} / \mathrm{s}$ was assumed for the seismic source. The slip rate function was a box-car with a rise time of $1 \mathrm{~s}$ and a total duration of $2.5 \mathrm{~s}$. The seismic moment $M_{0} 1.15 \times$ $10^{21} \mathrm{~N} \mathrm{~m}$ and thrust mechanism were assumed for the event (Ji and Hayes, 2008).

The discretization parameters used in this study are presented in Table 2. The spatial discretization in the three directions was $1 \mathrm{~km}$, and the time discretization was $0.03 \mathrm{~s}$. The number of grid points were 2400,1600 , and 300 for the X, Y, and Z directions (see Fig. 2), and a total of 20,000 time steps were used for a total simulation time of $600 \mathrm{~s}$. Table 2 includes the minimum $V_{P}$ and $V_{S}$ velocities, as well as the minimum density of the layers of the geologic structure of Figure 8. Notice that the spatial and temporal discretizations used, as well as the $V_{P_{\max }}$ of $8 \mathrm{~km} / \mathrm{s}$ of the geologic structure (Fig. 8), comply with the Courant-Friedrichs-Lewy (CFL) condition (i.e., a CFL of 0.24) to guarantee the stability and convergence of the solution (i.e., the synthetic velocity seismograms of the discretized media).

\section{Modeling Results}

General Observations. With the geologic, geophysical, seismic source, and discretization parameters discussed previously in this paper, the computation with the 3DOPFD code of the low-frequency synthetics for the 12 May $2008 M_{\mathrm{w}} 7.9$

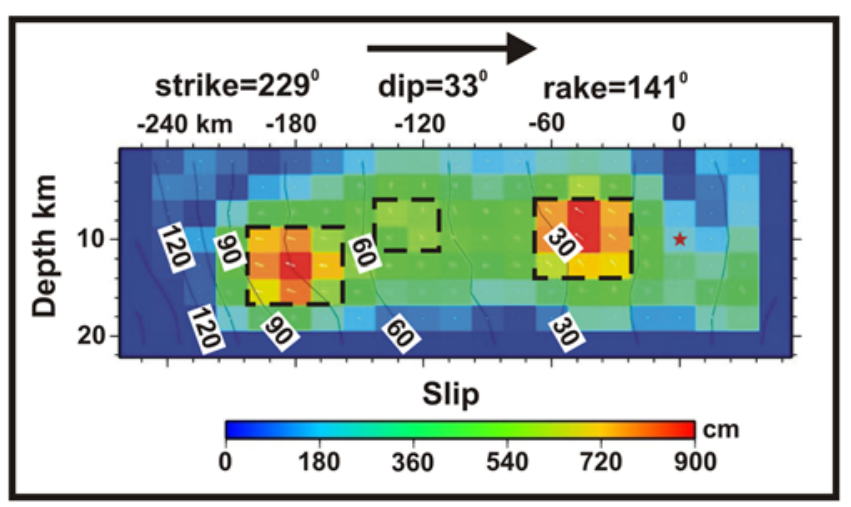

Figure 9. Kinematic slip and the strike, dip, and rake of the 12 May 2008 Wenchuan $M_{\mathrm{w}} 7.9$ earthquake proposed by Ji and Hayes (2008). Dashed line rectangles indicate the regions with slips from $\sim 6$ to $\sim 9 \mathrm{~m}$ (modified from the USGS Web site, see Data and Resources section). The color version of this figure is available only in the electronic edition.
Table 2

Parameters for the 3D Low-Frequency Modeling

\begin{tabular}{lc}
\hline \multicolumn{1}{c}{ Parameter } & Value \\
\hline Spatial discretization $(\mathrm{km})$ & 1.0 \\
Temporal discretization $(\mathrm{s})$ & 0.03 \\
$P$-wave minimum velocity $(\mathrm{km} / \mathrm{s})$ & 4.5 \\
$S$-wave minimum velocity $(\mathrm{km} / \mathrm{s})$ & 2.4 \\
Minimum density $\left(T o n / \mathrm{m}^{3}\right)$ & 2.5 \\
Number of grid points, $\mathrm{X}$ direction & 2400 \\
Number of grid points, Y direction & 1600 \\
Number of grid points, vertical direction & 300 \\
Number of time steps & 20000 \\
Simulation time (s) & 600 \\
\hline
\end{tabular}

Wenchuan earthquake was carried out on the supercomputers KanBalam and HECToR (see Data and Resources section).

The 3DOPFD code previously has been successfully used to obtain near-field and far-field low-frequency synthetics of the 19 September $1985 M_{s} 8.1$ Michoacan, Mexico, earthquake (Cabrera, et al., 2007; Chavez et al., 2008). For those studies, the authors used the slip distribution suggested by Mendoza and Hartzell (1989), who, for the source inversion of the 1985 Michoacan event, used nearfield and teleseismic waveform data low-pass filtered at $0.5 \mathrm{~Hz}$ and utilized 120 subfaults of $15 \times 13.9 \mathrm{~km}^{2}$, each of them to obtain the slip distribution of the event. Mendoza and Hartzell (1989) pointed out that the slip distribution they obtained could only model source frequencies $\leq 0.5 \mathrm{~Hz}$.

One of the numerical experiments performed by Cabrera, et al. (2007) for the 1985 Michoacan event consisted of using spatial discretizations in the three directions of 1.0, 0.5 , and $0.25 \mathrm{~km}$ of a $500 \times 600 \times 125 \mathrm{~km}^{3}$ physical domain and temporal discretizations of $0.03,0.02$, and $0.01 \mathrm{~s}$, respectively, in order to comply with the CFL condition. An important result of those studies was that, even though theoretically the computed synthetic seismograms (Cabrera, et al., 2007; Chavez et al., 2008) for the 0.5 and $0.25-\mathrm{km}$ spatial discretization should have a frequency content larger than $1 \mathrm{~Hz}$, the Fourier amplitude spectra of the corresponding synthetics had very small values at a frequency of $\sim 0.3 \mathrm{~Hz}(<0.5 \mathrm{~Hz})$ for all the previously mentioned space and temporal discretizations. This result is in agreement with Mendoza and Hartzell (1989), who emphasized the $0.5-\mathrm{Hz}$ limit of their source inversion.

Taking these results into account, as well as the fact that the slip distributions of $\mathrm{Ji}$ and Hayes (2008) for the $M_{\mathrm{w}} 7.9$ Wenchuan event were obtained with the inversion of teleseismic data and 168 subfaults of $15 \times 5 \mathrm{~km}^{2}$ each, to model the event $315 \times 40 \mathrm{~km}^{2}$ rupture area; therefore, the maximum frequency modeled for the Ji and Hayes (2008) source inversion is $0.5 \mathrm{~Hz}$ (Chen Ji, personal comm., 2010), as in the Mendoza and Hartzell (1989) inversion of the 1985 Michoacan earthquake. For these reasons, we decided to restrict our study to synthetics with frequencies up to $0.3 \mathrm{~Hz}$.

The main objective of this work was the 3D modeling of the low-frequency $(\leq 0.3 \mathrm{~Hz})$ wave propagation generated by 
the 12 May 2008 Wenchuan earthquake and then to compare the modeling results with different types of observations of the wave propagation and the effects of this event, particularly in the vicinity of the rupture zone of this earthquake, as follows: (1) to compare the synthetic seismograms with the ones observed at the near (MZQ accelerographic station site), intermediate (GYA VBB seismographic station site), and far (TIY VBB seismographic station site) field recordings; (2) to obtain 3D visualizations of the low-frequency synthetic velocity wave field for the region of interest, and particularly for the one surrounding the Longmen Shan fault system, where the effects of the wave propagation of the earthquake were the most important; (3) to compare the synthetics results with surface differential radar interferometry (DinSAR) ground deformation imagery available for specific zones of the Sichuan region; and (4) to compare the regional 3D synthetic velocities wave-field results with the Mercalli modified intensities observed mainly on and in the vicinity of the rupture zone of the 2008 Wenchuan event.

Comparison of Synthetic Seismograms with Seismograms Observed at the Near-Field, Intermediate-Field, and Far Field Recordings. For the comparisons of synthetics with the observations in Figures 10 and 11, we present examples of the type of results obtained from the modeling. Figure 10 includes the time domain comparisons for the three station sites, and the frequency domain comparisons are presented in Figure 11. In Figure 10a, the observed and synthetic velocity seismograms in the vertical $(Z)$ direction for the near field station MZQ, located at an epicentral distance of $\sim 90 \mathrm{~km}$ (Fig. 2) are shown. As mentioned previously in this paper, the observed velocity seismogram corresponds to a unsaturated recorded accelerogram with a total duration of $\sim 160 \mathrm{~s}$ (Fig. 7), recorded practically on top of the seismic source of the Wenchuan 2008 event, from which a 100-s window was selected.

The window of the observed seismogram includes the first arrivals, as well as the surface and the coda waves, propagating from the source to the MZQ site. As the triggering time of the accelerograph of the MZQ station was not available, the $S$-wave arrival time on both seismograms was chosen as the criteria for selecting the starting time for the synthetic. Notice in Figure 10a that the overall shape and the maximum amplitudes of both the observed and the synthetic seismograms are similar, particularly for the first arrivals and the surface wave (i.e., up to $50 \mathrm{~s}$ ); however, from 50 to $60 \mathrm{~s}$, the synthetic amplitudes are larger than the observed ones, and the opposite occurs from 60 to $100 \mathrm{~s}$.

With respect to the phase comparisons of the observed and synthetic signals, we observe some phase differences on the surface and coda waves of the synthetic with respect to the observed record. The comparison of the observed and the synthetic seismograms in the frequency domain is shown in Figure 11a. From this figure it can be concluded that, as a whole, the shapes of the spectra are similar, although the Fourier amplitudes of the synthetic are about half of the (a)

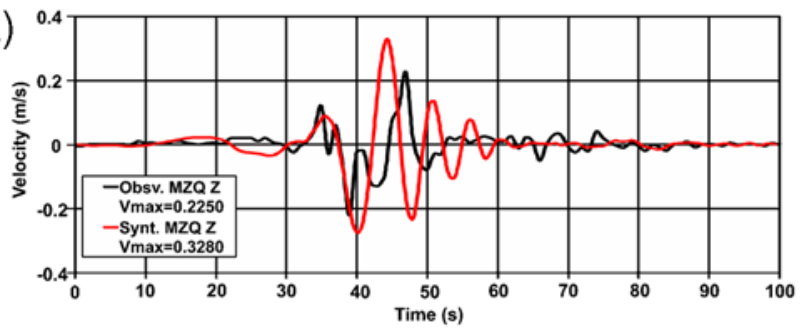

(b)

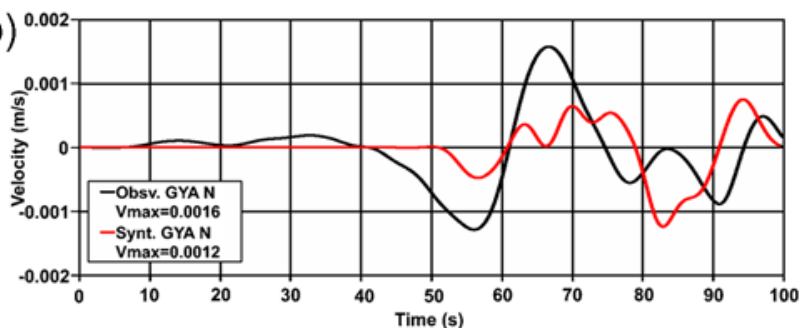

(c)

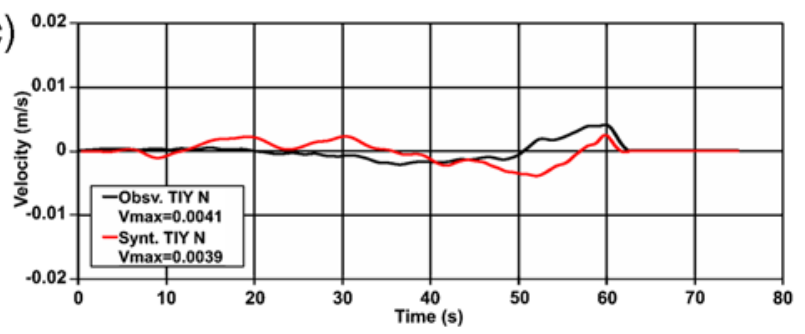

Figure 10. Observed and synthetic velocity seismograms $(\leq 0.3 \mathrm{~Hz})$ for the 12 May 2008 Wenchuan $M_{\mathrm{w}} 7.9$ earthquake: (a) in the vertical (Z) direction for station MZQ, epicentral distance $90 \mathrm{~km}$ (see Fig. 2); (b) in the north (N) direction for station GYA, epicentral distance of $500 \mathrm{~km}$ (see Fig. 2); (c) in the north (N) direction for station TIY, epicentral distance of $1200 \mathrm{~km}$ (see Fig. 2). The color version of this figure is available only in the electronic edition.

observed for $f \leq 0.04 \mathrm{~Hz}$, up to twice as high from 0.06 to $0.1 \mathrm{~Hz}$, up to four times (at $0.15 \mathrm{~Hz}$ ) higher between 0.1 and $0.2 \mathrm{~Hz}$, and the same from 0.2 to $0.25 \mathrm{~Hz}$.

We think that the results obtained for the MZQ synthetics from the 3D modeling are reasonable, taking into consideration that: (1) the actual local soil conditions at the station site are unknown and that they have been only approximately incorporated by the geologic structure adopted in this work, particularly by the $V_{S}$ velocities of the first 4-km layer (from the top) shown in Figure 8; (2) the topography effects on the station site seismic response have not been included in the flat layering (Fig. 8) modeling used herewith; and (3) the assumptions made about a uniform rupture velocity of the seismic source of a complex geology region such as the Longmen Shan fault system and the Sichuan region as a whole, as Robert et al. (2009) and Densmore et al. (2007) have pointed out.

The comparison of the time and frequency domains for the observed and synthetic seismograms for the intermediate field (500-km epicentral distance), VBB seismographic GYA station is shown in Figure 10b and Figure 11b, respectively. As noted previously, the observed seismogram corresponds to a 100-s window of the unsaturated part of the 1800-s record (see Fig. 5); therefore, the modeling for this station 
(a)

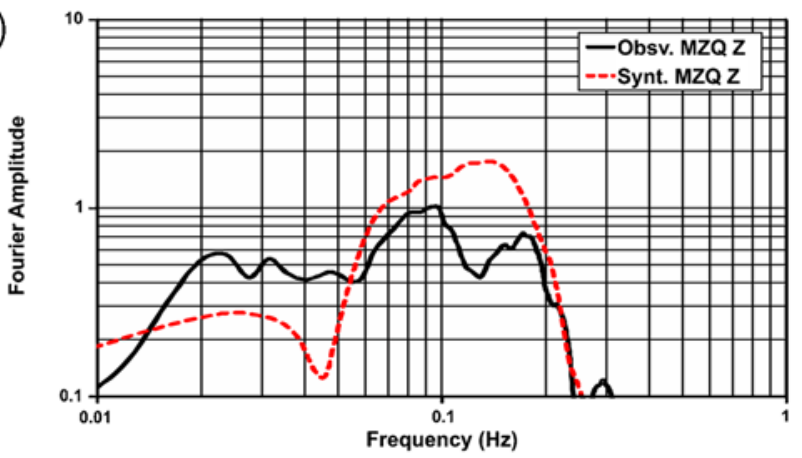

(b)

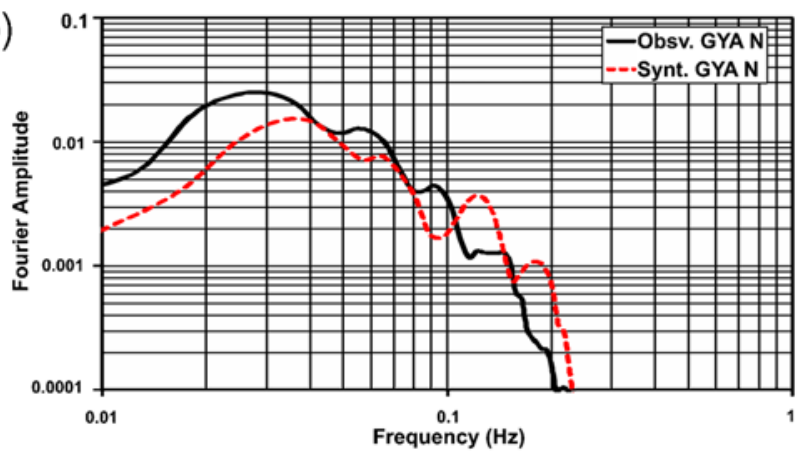

(c)

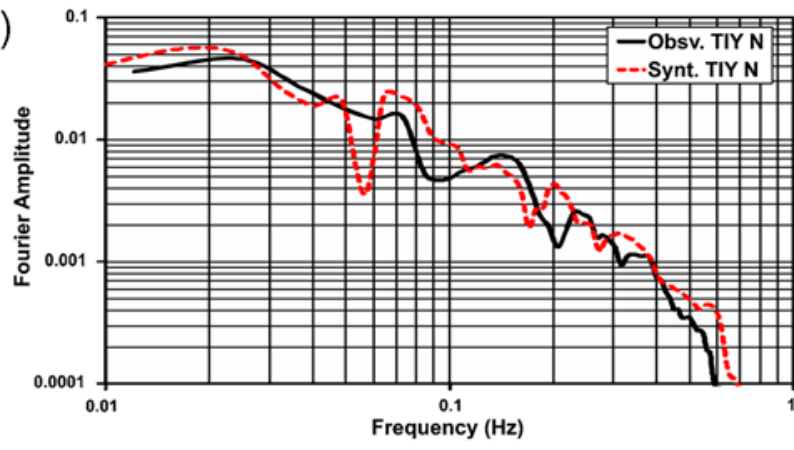

Figure 11. Fourier amplitude spectra for the seismograms of Figure 10. The color version of this figure is available only in the electronic edition.

aims to generate the synthetics corresponding to the first arrivals. From the comparison in the time domain shown in Figure 10b, it can be concluded that the overall shapes of both the observed and the synthetic seismograms are similar; however, from 0 to $70 \mathrm{~s}$, the maximum amplitudes of the synthetic are about $60 \%$ of the observed ones, and between 70 and $100 \mathrm{~s}$, the amplitudes are very similar. There are some differences in the phases of the synthetic with respect to the observed one. With respect to the frequency domain comparison, from Figure 11b, we observe that their shapes are very similar and that, from 0.01 to $0.10 \mathrm{~Hz}$, the Fourier amplitudes of the observed seismograms are higher (up to 60\%) than the corresponding amplitudes of the synthetics; however, from 0.1 to $0.2 \mathrm{~Hz}$, the synthetic Fourier amplitudes are higher than the corresponding observed ones.

From the time and frequency domain comparisons of the GYA seismograms, we can conclude that the results are, as a whole, acceptable for the same reasons that were mentioned earlier with respect to the MZQ synthetic. However, we think that for station GYA the adopted geologic structure of Figure 8, specially of the most surficial layers, the effects of not knowing the actual superficial layering and its properties becomes critical; therefore, the differences between the time and frequency domain characteristics of the synthetic and the observed seismograms have to be larger than for MZQ.

The comparison of the time and frequency domains for the observed and synthetic seismograms for the far $(1200-\mathrm{km}$ epicentral distance) field, VBB seismographic TIY station is shown in Figure 10c and Figure 11c, respectively. The observed seismogram correspond to a 60 -s window of the unsaturated part of a 1800-s record (see Fig. 6); therefore, the modeling objective for this station consists of the generation of the synthetic corresponding to the first arrivals. From the comparison in the time domain shown in Figure 10c, we observe that, even though the amplitudes are similar, the phase differences of the two signals are large. With respect to the frequency domain comparison from Figure 11c, we observe that their shape is very similar and that the Fourier amplitudes of the observed and synthetic seismograms are close from 0.01 to $0.5 \mathrm{~Hz}$. From those comparisons, we can conclude that the modeling results for TIY station are acceptable, better in the frequency domain than in the time domain. We think that the reasons for these are basically the same as that already mentioned for station GYA.

$3 D$ Visualizations of the Low-Frequency Synthetic Velocities Wave Field for the Region of Interest. With respect to the 3D low-frequency synthetic velocities wave field for the region of interest, in Figures 12-14, 3D snapshots at $t=24.24$, 72.24 , and $100.56 \mathrm{~s}$ of the synthetic velocities wave fields $(\leq 0.3 \mathrm{~Hz})$ in the $\mathrm{Y}$ direction, obtained for the 12 May 2008 $M_{\mathrm{w}} 7.9$ Wenchuan earthquake modeling are shown, respectively. The visualizations were obtained for a reduced domain of $900 \times 800 \times 70 \mathrm{~km}^{3}$ because the amplitudes of the velocities wave field were too small to be visualized for the original $2400 \times 1600 \times 300 \mathrm{~km}^{3}$ of Figure 2. Notice that the maximum and minimum velocities are in the $M_{\mathrm{w}} 7.9$ Wenchuan earthquake rupture direction ( $\mathrm{X}$ direction, parallel to the strike of the event) and perpendicular to it (Y direction), respectively. This observation from the synthetic wave propagation pattern obtained here corresponds to the important infrastructure destruction observed for towns such as Yingxiu, Dujiangyang, and Beichuan, as well as to the very slight damage observed at Chengdu (see Figs. 12-14 for the towns' locations) and reported by Yuan and Sun, 2008. From other results not shown here, the following conclusions can be mentioned: (1) the largest amplitudes in the $\mathrm{X}, \mathrm{Y}$ and $\mathrm{Z}$ synthetic velocity wavefields occurred in the positive $X$ direction, which correspond to the rupture direction of the Wenchuan earthquake reported by the USGS Web site (see Data and Resources section); (2) the smaller amplitudes in the $\mathrm{X}$ and $\mathrm{Y}$ wavefields occurred in a cone-shaped volume generated by a $30^{\circ}$ angle (for the $\mathrm{X}$ wavefield) to $60^{\circ}$ angle (for the $\mathrm{Y}$ wavefield), approximately in the $\mathrm{Y}$ direction. 


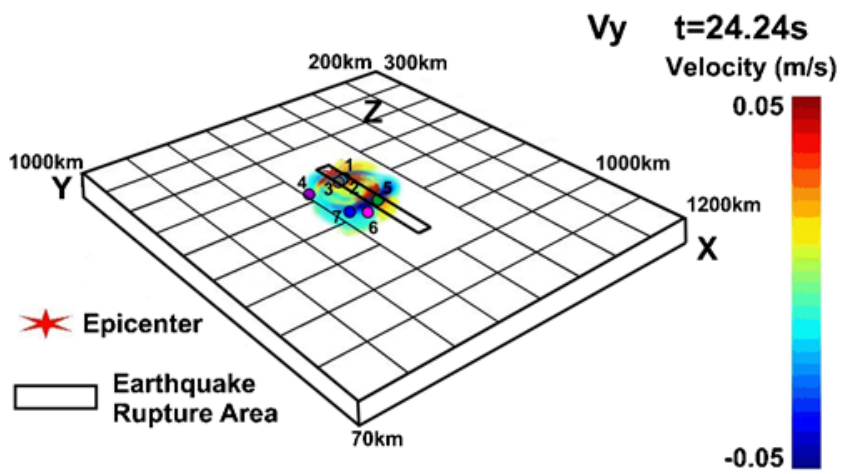

Figure 12. 3D Snapshot (reduced for visualization purposes to $900 \times 800 \times 70 \mathrm{~km}^{3}$ of the modeled volume; see Fig. 2) at $t=$ $24.24 \mathrm{~s}$ of the synthetic velocities wave field $(\leq 0.3 \mathrm{~Hz})$ in the Y direction for the 12 May 2008 Wenchuan $M_{\mathrm{w}} 7.9$ earthquake. The darker and thicker wave field identifies the southwest-northeast rupture direction of the Wenchuan event. Points 1 to 7 correspond to the locations of Yingxiu, Zipingku, Dujiangyang, Chengdu, Beichuan, Jiangyou, and Mianyang, respectively. The color version of this figure is available only in the electronic edition.

Comparison of Synthetics Results with Surface DinSAR Ground Deformation Imagery. For comparison of the synthetics results with DinSAR images available for specific zones of the Sichuan region for the $M_{\mathrm{w}} 7.9$ Wenchuan earthquake (Figure 15 and Figure 16), we show the low-frequency synthetic displacement seismograms obtained for the towns of Chengdu and Beichuan. Notice in Figure 15 that a maximum displacement, $D_{\max }$, of $\sim 0.12 \mathrm{~m}$ was obtained at Chengdu for the $\mathrm{X}$ and $\mathrm{Y}$ directions and of $\sim 0.07 \mathrm{~m}$ for the $\mathrm{Z}$ direction and that permanent displacements of $\sim-0.04 \mathrm{~m}$ for the $\mathrm{Y}$ direction and of $\sim-0.03$ for the $\mathrm{Z}$ direction were obtained in the modeling. The corresponding results for Beichuan are the following: $D_{\max }$ values of $-0.71,-3.31$, and $+2.87 \mathrm{~m}$ for the $\mathrm{X}, \mathrm{Y}$, and $\mathrm{Z}$, directions, respectively;

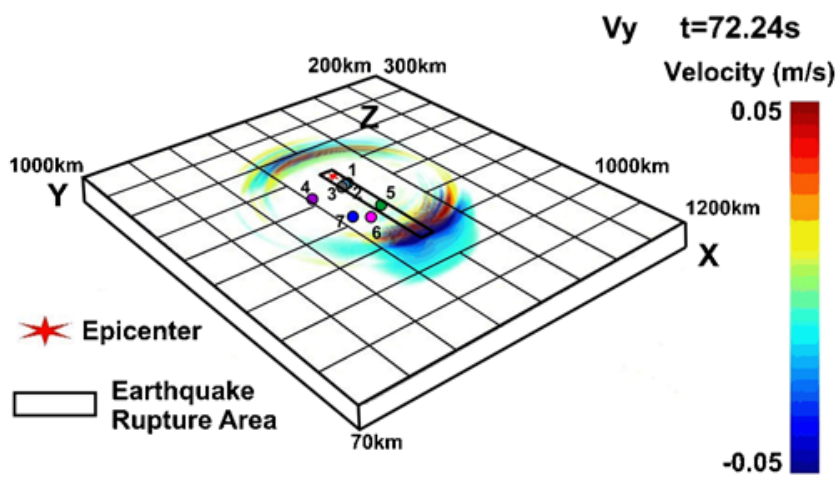

Figure 13. 3D snapshot (reduced for visualization purposes to $900 \times 800 \times 70 \mathrm{~km}^{3}$ of the modeled volume; see Fig. 2) at $t=$ $72.24 \mathrm{~s}$ of the synthetic velocities wave field $(\leq 0.3 \mathrm{~Hz})$ in the Y direction for the 12 May 2008 Wenchuan $M_{\mathrm{w}} 7.9$ earthquake. The darker and thicker wave field identifies the southwest-northeast rupture direction of the Wenchuan event. Points 1 to 7 correspond to the locations of Yingxiu, Zipingku, Dujiangyang, Chengdu, Beichuan, Jiangyou, and Mianyang, respectively. The color version of this figure is available only in the electronic edition.

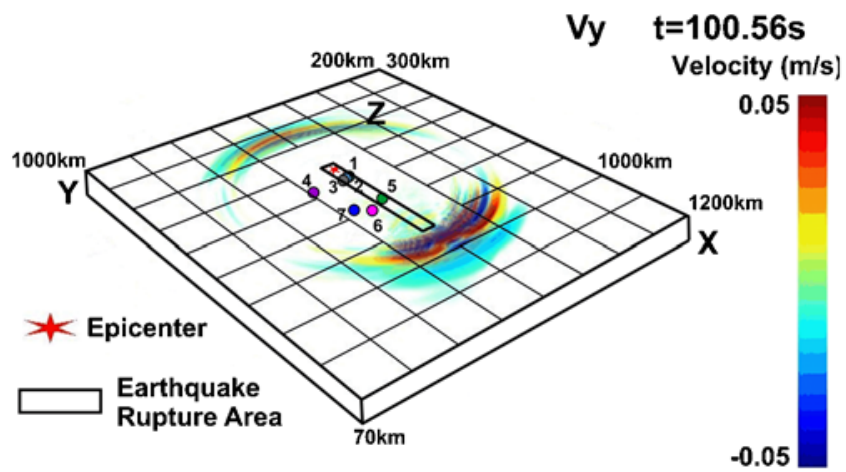

Figure 14. 3D snapshot (reduced for visualization purposes to $900 \times 800 \times 70 \mathrm{~km}^{3}$ of the modeled volume; see Fig. 2) at $t=$ $100.56 \mathrm{~s}$ of the synthetic velocities wave field $(\leq 0.3 \mathrm{~Hz})$ in the Y direction for the 12 May 2008 Wenchuan $M_{\mathrm{w}} 7.9$ earthquake. The darker and thicker wave field identifies the southwest-northeast rupture direction of the Wenchuan event. Points 1 to 7 correspond to the locations of Yingxiu, Zipingku, Dujiangyang, Chengdu, Beichuan, Jiangyou, and Mianyang, respectively. The color version of this figure is available only in the electronic edition.

maximum permanent displacements are $\sim+0.4, \sim-1.5$, and $\sim+0.45 \mathrm{~m}$ in the $\mathrm{X}, \mathrm{Y}$, and $\mathrm{Z}$ directions, respectively.

The comparison of synthetic displacements obtained for Beichuan and Chengdu with DinSAR ground deformation imagery (Fig. 17) is as follows. The DinSAR ground deformations results reported for the Beichuan region are of $-5 \mathrm{~m}$ to $+5 \mathrm{~m}$, and specially of $-1 \mathrm{~m}$ to $+1 \mathrm{~m}$, which are of the order of the maximum permanent synthetic displacements consigned for Beichuan. Finally, from the same figure it can be observed that the DinSAR ground deformations result reported for the vicinity of the Chengdu region is of $0.12 \mathrm{~m}$, which is also of the order of the maximum permanent synthetic displacements values of the synthetics for this town. From these results, we think that the comparisons of the synthetic displacements obtained in this work are in reasonable agreement with the DinSAR results of Ge et al. (2008) and Stramondo et al. (2008) for the 2008 Wenchuan earthquake, taking into account what we already mentioned previously in this paper with respect to the comparisons of the synthetics

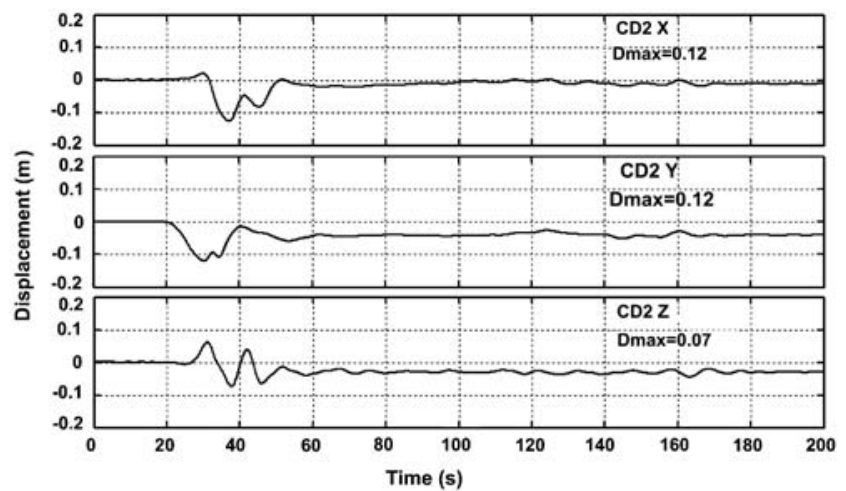

Figure 15. Displacement synthetics of the 12 May 2008 Wenchuan $M_{\mathrm{w}} 7.9$ earthquake obtained for seismographic station site CD2 (Chengdu; see Fig. 17). 


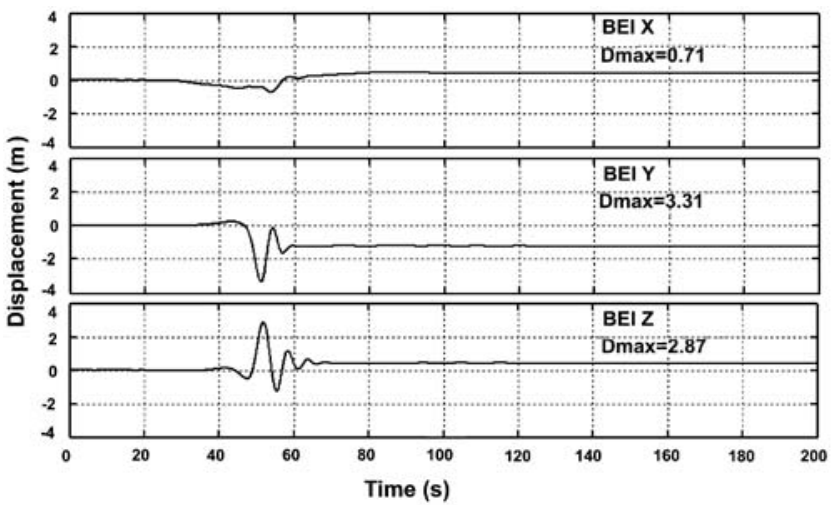

Figure 16. Displacement synthetics of the 12 May 2008 Wenchuan $M_{\mathrm{w}} 7.9$ earthquake obtained for Beichuan (see Fig. 17).

with the observed seismograms for the recording stations sites of MZQ, GYA, and TIY.

Comparison of Regional 3D Synthetic Velocities Wave-Field Results with Mercalli Modified Intensities Observed on and near the Rupture Zone. With respect to the comparison of the regional 3D synthetic maximum velocities wave-field results with the Mercalli modified intensities (MMI) observed mainly on and in the vicinity of the rupture zone of the 2008 Wenchuan event, the comparison of the maximum synthetic velocity patterns in the $\mathrm{Y}$ direction with the MMI isoseist of the 2008 Wenchuan earthquake (reported in fig. 3.1 in Yuan and Sun, 2008) is presented in Figure 18. Notice, in this figure, that the maximum synthetic velocities globally correspond with the zones where the reported intensities were X and XI, as for example in Beichuan; the same observation applies to the minimum synthetic velocities with the zone of intensities VI, such as in Chengdu; however, there is a discrepancy for the epicentral region, where a regional MMI of XI was observed versus an MMI of IX associated with the maximum synthetic velocity. (See the right side of the figure for the relationship between the ground velocity and MMI.) Nevertheless, from these results, we think that the comparisons of the regional 3D synthetic maximum velocities wavefield results with the MMI (observed mainly on and in the vicinity of the rupture zone) of the 2008 Wenchuan event are as whole reasonable, if we take into account what we already mentioned with respect to the comparisons of the synthetic with the observed seismograms for the recording station site of MZQ.

\section{Conclusions}

A recently optimized 3D seismic wave propagation parallel finite-difference code was used to obtain low-frequency $(\leq 0.3 \mathrm{~Hz}) 3 \mathrm{D}$ synthetic seismograms for the 12 May 2008 $M_{\mathrm{w}} 7.9$ Wenchuan earthquake. The synthetics were obtained on the surface projection of a volume of $2400 \times 1600 \times$ $300 \mathrm{~km}^{3}$; the volume included the $40 \times 315 \mathrm{~km}^{2}$ kinematic description of the earthquake rupture. The spatial and temporal modeling discretizations were $1-\mathrm{km}$ and $0.03 \mathrm{~s}$, respectively. The comparison between the observed and synthetic

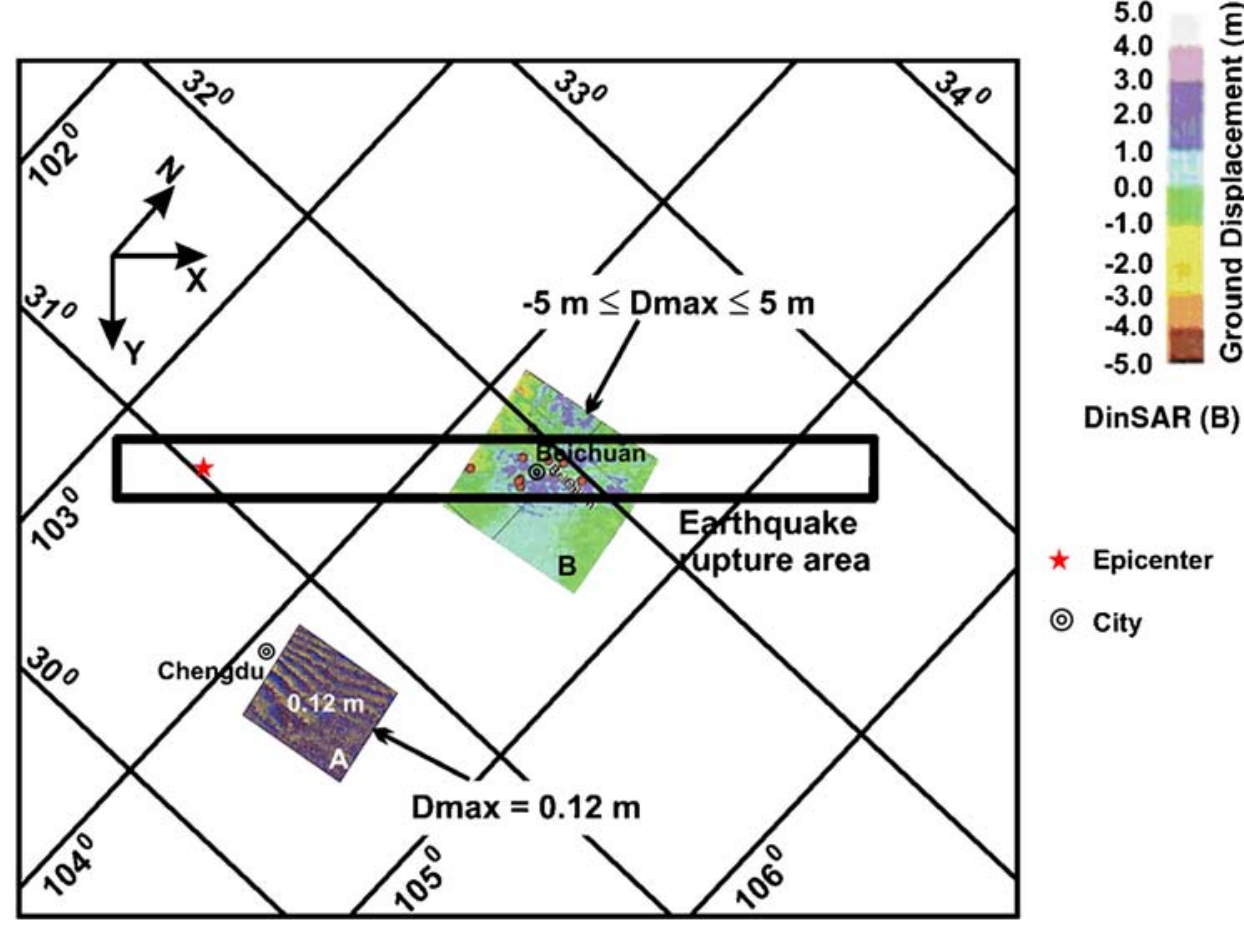

Figure 17. Maximum ground displacements near Chengdu and Beichuan using DinSAR ground deformation imagery (A, Stramondo et al., 2008; B, Ge et al., 2008) for the 12 May $2008 M_{\mathrm{w}} 7.9$ Wenchuan earthquake. The color version of this figure is available only in the electronic edition. 
$V \max Y$

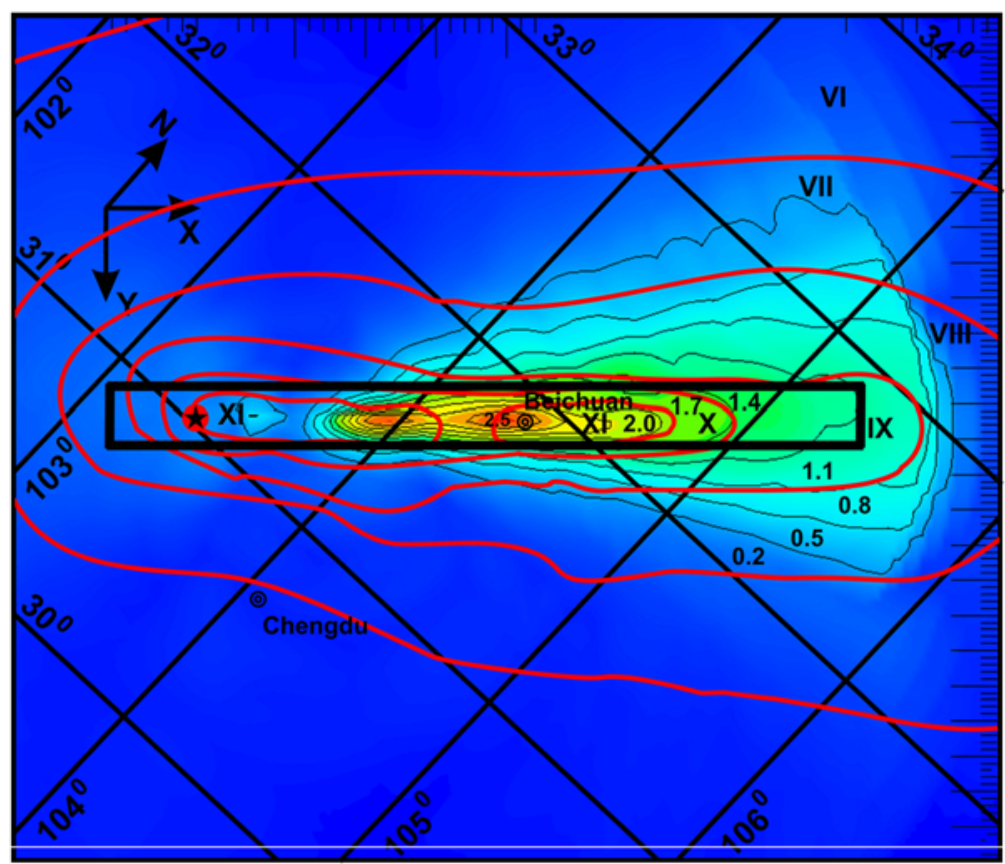

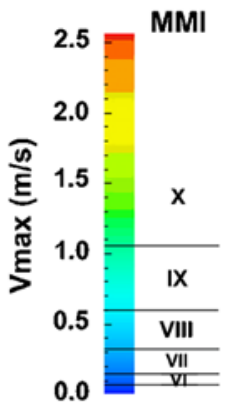

Epicenter

๑) City

- Obsv. site

Olsoseist

$\square$ rupture area

$\sum_{0.2}$ Isovelocity

Figure 18. Comparison of the maximum synthetic velocities propagation pattern (isovelocities $V_{\max }$ ) in the $\mathrm{Y}$ direction with the Mercalli modified intensity isoseist (fig. 3.1 in Yuan and Sun, 2008) of the 12 May 2008 Wenchuan $M_{\mathrm{w}} 7.9$ earthquake. The color version of this figure is available only in the electronic edition.

seismograms for several station sites of the Seismological and Accelerographic Networks of China (MZQ, GYA, and TIY) located at about 90, 500, and $1200 \mathrm{~km}$ from the epicenter of the Wenchuan event, respectively, is acceptable. The comparisons of the maximum permanent synthetic displacements with DinSAR ground deformation imagery, as well as of maximum velocity synthetic patterns with Mercalli modified intensity isoseists of the 2008 Wenchuan earthquake are also acceptable. From the 3D visualizations of the propagation of the modeled earthquake obtained in this work, the largest amplitudes in the $\mathrm{X}$ (rupture direction), $\mathrm{Y}$ (perpendicular to $\mathrm{X}$ ), and $\mathrm{Z}$ velocity wave fields occurred in the rupture direction of the Wenchuan earthquake. These results partially explain the extensive damage observed on the infrastructure and towns located on top and in the neighborhood of the Wenchuan earthquake rupture zone.

\section{Data and Resources}

The supercomputers KanBalam (Universidad Nacional Autónoma de México, Mexico) and HECToR (UK National Supercomputing Service) were used to run the code. The seismograms used in this study were provided by the Seismological Network of China and the accelerogram from station MZQ by the China Digital Strong Motion Network, and they cannot be released to the public. The kinematic slip distribution, the strike, dip, and rake of the 2008 Wenchuan earthquake were obtained from the U.S. Geological Survey Preliminary Result of the May 12, 2008, $M_{\mathrm{w}} 7.9$ Eastern
Sichuan, China, Earthquake, Finite Fault Model using http://earthquake.usgs.gov/earthquakes/eqinthenews/2008/ us2008ryan/ (last accessed May 2008).

\section{Acknowledgments}

We would like to thank J. L. Gordillo, G. Lucet, and the supercomputing staff of the Dirección General de Cómputo Acádemico (DGSCA), UNAM, as well as M. Ambriz and the computing staff of the Institute of Engineering, UNAM, for their support. Also, we would like to thank E. Chavez for helping us to obtain the seismological information of the Wenchuan earthquake in May-June 2008. We acknowledge DGSCA, UNAM for the support to use KanBalam, and the facilities of HECToR, the UK's national high-performance computing service, which is provided by UoE HPCx Ltd at the University of Edinburgh, Cray Inc., and NAG Ltd, and funded by the Office of Science and Technology through the Engineering and Physical Sciences Research Council's High End Computing Programme. The authors also acknowledge support from the Scientific Computing Advanced Training (SCAT) project through Europe Aid contract II-0537-FC-FA (http:// www.scat-alfa.eu). Thoughtful reviews from anonymous reviewers significantly improved the manuscript.

\section{References}

Aagaard, B. T., T. M. Brocher, D. Dolenc, D. Dreger, R. W. Graves, S. Harmsen, S. Hartzell, S. Larsen, and M. L. Zoback (2008a). Ground-motion modeling of the 1906 San Francisco earthquake, Part I: Validation using the 1989 Loma Prieta earthquake, Bull. Seismol. Soc. Am. 98, no. 2, 989-1011, doi 10.1785/0120060409.

Aagaard, B. T., T. M. Brocher, D. Dolenc, D. Dreger, R. W. Graves, S. Harmsen, S. Hartzell, S. Larsen, K. McCandless, S. Nilsson, N. A. Petersson, A. Rogers, B. Sjogreen, and M. L. Zoback (2008b). Ground-motion modeling of the 1906 San Francisco earthquake, 
Part II: Ground-motion estimates for the 1906 earthquake and scenario events, Bull. Seismol. Soc. Am. 98, no. 2, 1012-1046, doi 10.1785/ 0120060410.

Burchfiel, B. C., L. H. Royden, R. D. van der Hilst, Z. Chen, R. W. King, C. Li, J. Lu, H. Yao, and E. Kirby (2008). A geological and geophysical context for the Wenchuan earthquake of 12 May 2008, Sichuan, People's Republic of China, GSA Today 18, no. 7, doi 10.1130/GSATG18A.1.

Cabrera, E., M. Chavez, R. Madariaga, N. Perea, and M. Frisenda (2007). 3D parallel elastodynamic modeling of large subduction earthquakes, Lect. Notes Comput. Sci. 4757, 373-380.

Chavez, M., E. Cabrera, R. Madariaga, N. Perea, Ch. Moulinec, D. Emerson, M. Ashworth, and A. Salazar (2008). Benchmark study of a 3D parallel code for the propagation of large subduction earthquakes, Lect. Notes Comput. Sci. 5205, 303-310.

Custodio, S., M. T Page, and R. J. Archuleta (2009). Constraining earthquake source inversions with GPS data: 2. A two-step approach to combine seismic and geodetic datasets, J. Geophys. Res. 114, B01315, doi 10.1029/2008JB005746.

Densmore, A. L., M. A. Ellis, Y. Li, R. Zhou, G. S. Hancock, and N. Richardson (2007). Active tectonics of the Beichuan and Pengguan faults at the eastern margin of the Tibetan Plateau, Tectonics 26, TC4005, doi 10.1029/2006TC001987.

Ge, L., K. Zhang, Y. Dong, H. Chang, and C. Rizos (2008). Preliminary results of satellite radar interferometry for the co-seismic deformation of the 12 May $2008 M_{s} 8.0$ Wenchuan earthquake, Geogr. Inf. Sci. 14, 12-19.

Graves, R. W. (1996). Simulating seismic wave propagation in 3D elastic media using staggered-grid finite differences, Bull. Seismol. Soc. Am. 86, 1091-1106.

Ji, C., and G. Hayes (2008). Preliminary result of the May 12, 2008, $M_{\mathrm{w}} 7.9$ eastern Sichuan, China earthquake, finite fault model, available at http:// earthquake.usgs.gov/earthquakes/eqinthenews/2008/us2008ryan/ finite_fault.php (last accessed May 2008).

Levander, A. R. (1988). Fourth-order finite-difference $P-S V$ seismograms, Geophysics 53, 1425-1436.

Li, S., W. D. Mooney, and J. Fan (2006). Crustal structure of mainland China from deep seismic sounding data, Tectonophysic 420, 239-252.

Liu, P., S. Custodio, and R. J. Archuleta (2006). Kinematic inversion of the $2004 M_{\mathrm{w}} 6.0$ Parkfield earthquake including an approximation to site effects, Bull. Seismol. Soc. Am. 96, no. 4B, S143-S158, doi 10.1785/ 0120050826.

Madariaga, R. (1976). Dynamics of an expanding circular fault, Bull. Seismol. Soc. Am. 67, 163-182.

Mendoza, C., and S. Hartzell (1989). Slip distribution of the 19 September 1985 Michoacan, Mexico, earthquake: Near source and teleseismic constraints, Bull. Seismol. Soc. Amer. 79, 655-699.

Minkoff, S. E. (2002). Spatial parallelism of a 3D finite difference velocitystress elastic wave propagation code, SIAM J. Sci. Comput. 24, 1-19.

Moczo, P. (1989). Finite-difference technique for $S H$-waves in 2-D media using irregular grids-application to the seismic response problem, Geophys. J. Int. 99, 321-329.

Moczo, P., J. Kristek, and L. Halada (2005). The finite-difference method for seismologists-An introduction, Web site of the Marie Curie training network SPICE of the European Commission, available at www.spicertn.org/library/training-material/index.html (last accessed April 2009).

Olsen, K. B. (1994). Simulation of three-dimensional wave propagation in the Salt Lake Basin, Ph.D. Thesis, University of Utah at Salt Lake City, $157 \mathrm{p}$.

Olsen, K. B., R. J. Archuleta, and J. R. Matarese (1995). Three-dimensional simulation of a magnitude 7.75 earthquake on the San Andreas fault, Science 270, 1628-1632.

Olsen, K. B., R. Madariaga, and R. J. Archuleta (1997). Three-dimensional dynamic simulation of the 1992 Landers earthquake, Science 278, 834-838.
Pitarka, A. (1999). 3D elastic finite-difference modeling of seismic motion using staggered grids with nonuniform spacing, Bull. Seismol. Soc. Am. 89, 54-68.

Robert, A., J. Zhu, J. Vergne, R. Cattin, L. S. Chan, G. Wittlinger, G. Herquel, J. de Sigoyer, M. Pubellier, and L. D. Zhu (2009). Crustal structures in the area of the 2008 Sichuan earthquake from seismologic and gravimetric data, Tectonophysics, doi 10.1016/j.tecto.2009.11.010.

Stramondo, S., M. Chini, S. Salvi, C. Bignami, S. Zoffoli, and E. Boschi (2008). Ground deformation imagery of the May Sichuan earthquake, Eos Trans. AGU 89, no. 37, 341-342.

Virieux, J. (1984). $S H$-wave propagation in heterogeneous media: Velocitystress finite-difference method, Geophysics 49, 1933-1957.

Virieux, J. (1986). $P-S V$ wave propagation in heterogeneous media: Velocity-stress finite-difference method, Geophysics 51, 889-901.

Wang, C. Y., W. B. Han, J. P. Wu, H. Lou, and W. W. Chan (2007). Crustal structure beneath the eastern margin of the Tibetan Plateau and its tectonic implications, J. Geophys. Res. 112, B07307, doi 10.1029/ 2005JB003873.

Xu, L., S. Rondenay, and R. D. van der Hilst (2007). Structure of the crust beneath the southeastern Tibetan plateau from teleseismic receiver functions, Phys. Earth Planet. In. 165, 176-193, doi 10.1016/j. pepi.2007.09.002

Yuan, Y., and B. Sun (2008). General Introduction to Engineering Damage during Wenchuan Ms 8.0 Earthquake, J. Earthq. Eng. Eng. Vib. (Dizhen Gongcheng yи Gongcheng Zhendong), ISSN 1000-1301, 28 (Suppl.), 15-21 (special issue in English).

Institute of Engineering

Universidad Nacional Autónoma de México

Ciudad Universitaria, 04510

Mexico DF, Mexico

(M.Ch., N.P.)

Dirección General de Servicios de Cómputo Académico

Universidad Nacional Autónoma de México

Ciudad Universitaria, 04510, Mexico DF, Mexico (E.C., A.S.)

Laboratoire de Géologie

Centre National de la Recherche Scientifique

Ecole Normale Superieure

Département des Géosciences

24 Rue Lhomond, Paris, France

(R.M.)

China Earthquake Network Center

63 Fuxing Rd.

Beijing 100036, People's Republic of China (H.C., M.W., G.Z.)

STFC Daresbury Laboratory

Daresbury Science \& Innovation Campus

Warrington WA4 4AD, UK

(D.E., M.A., C.M.)

Institute of Engineering Mechanics, Chinese Academy of Sciences China Earthquake Administration

29 Xuefu Rd.

Harbin 150080, People's Republic of China

(X.L.)

Manuscript received 31 August 2009 